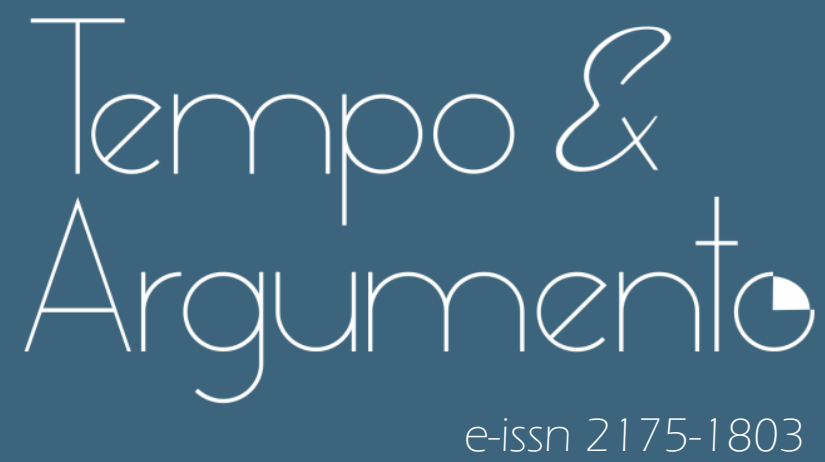

\title{
O uso da imprensa como fonte historiográfica e a ditadura no interior do Paraná
}

\section{Entrevista com}

- Carla Luciana Silva

Doutora em História pela Universidade Federal Fluminense (UFF).

Professora da Universidade Estadual do Oeste do Paraná (UNIOESTE).

Marechal Candido Rondon, PR - BRASIL

lattes.cnpq.br/2157223899184311

carlalusi@gmail.com

(D) orcid.org/0000-0001-6838-0394

Entrevista concedida ̀̀

$\otimes$ Lucas Alves da Silva

Doutorando no Programa de Pós-Graduação em História da Universidade do

Estado de Santa Catarina (UDESC)

Campo Mourão, PR - BRASIL

lattes.cnpq.br/2117390343566169

lucas.as137@gmail.com

(D) orcid.org/0000-0002-3878-4029

Para citar esta entrevista:

SILVA, Carla Luciana. O uso da imprensa como fonte historiográfica e a ditadura no interior do Paraná. [Entrevista realizada em 29 de setembro de 2020]. Revista Tempo e Argumento, Florianópolis, v. 13, n. 32, e0301. jan./abr. 2021.

Entrevistador: SILVA, Lucas Alves da.

dx.doi.org/10.5965/2175180313322021e0301 


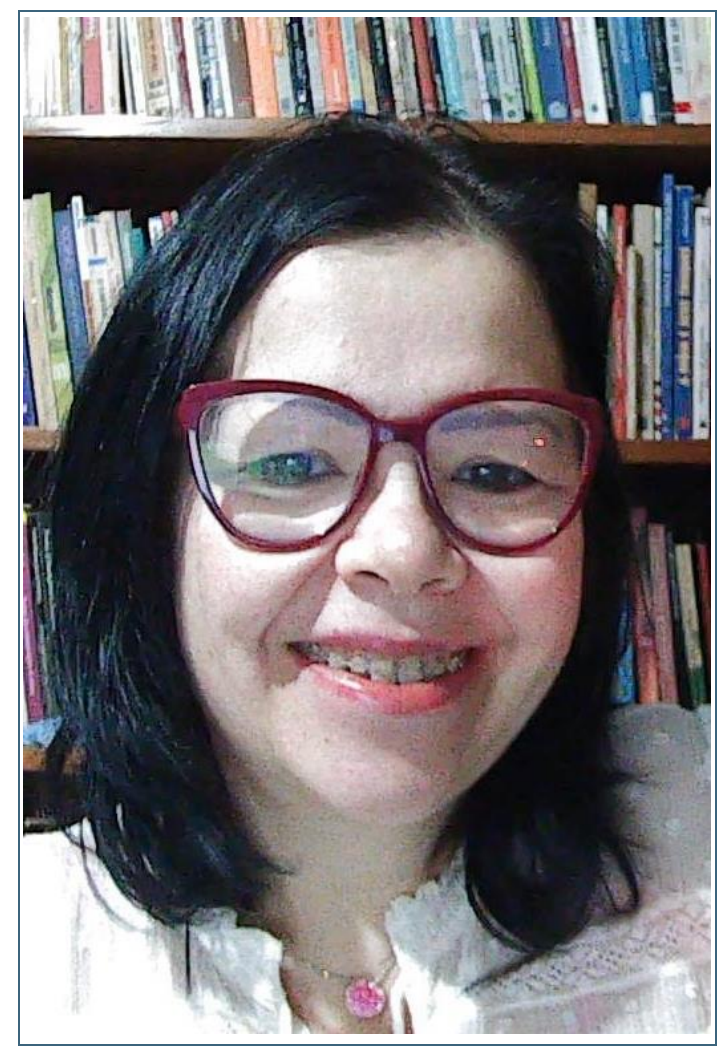

Carla Luciana Silva é professora associada da Universidade Estadual do Oeste do Paraná (UNIOESTE), campus de Marechal Candido Rondon, desde 1999. Atua no Programa de PósGraduação em História da UNIOESTE, na Linha de Pesquisa Estado e Poder. Possui doutorado em História pela Universidade Federal Fluminense (UFF) (2005), pós-doutorado pela Universidade Nova de Lisboa (2011-2012) e pósdoutorado pela UFF (2019-2020). Coordenou o projeto História e Análise Midiática, e coordena - projeto Ditadura no Oeste do Paraná e coordena o projeto de pesquisa intitulado A Vanguarda Popular Revolucionária (VPR) no Conesul (Fundação Araucária). Autora de $A$ Revolução da Vanguarda Popular Revolucionária (VRP), a ser publicado em 2021 pela editora Navegando e de Veja: o indispensável partido neoliberal (Edunioeste, 2009).

29 de setembro de 2020, dia em que o mundo ultrapassou a triste barreira de 1 milhão de mortos vítimas do novo coronavírus, e o Brasil ultrapassou a marca de 140 mil vidas perdidas pela mesma causa. Foi justamente nessa data que realizei a entrevista com a professora Carla Luciana Silva. Em virtude do necessário distanciamento social, a entrevista foi realizada via plataforma virtual, com início às 14h. Tanto a professora Carla, quanto eu, estávamos no estado do Paraná; ela, na cidade de Marechal Cândido Rondon e, eu, em Campo Mourão, cada um na sua respectiva residência. Na data da entrevista, mesmo sendo início da primavera, vale destacar que fazia um calor atípico para o período, e na cidade de Campo Mourão era possível notar um céu nublado, não por conta de uma possível chuva, que, inclusive, demorou a chegar, mas em razão das intensas queimadas que estavam ocorrendo naquele momento no Pantanal-sul-mato-grossense, as quais deixaram um rastro de destruição, espalhando sua fumaça por milhares de quilômetros e fazendo arder em chamas parte da vida lá existente. Mas esse é mais um triste assunto, dentre os vários que o ano de 2020 propiciou.

A atividade que resultou nesta entrevista está ligada à disciplina História do Tempo Presente: Teoria e Historiografia, ministrada pelo professor Rogério Rosa Rodrigues, no curso de doutorado do Programa de Pós-Graduação em História (PPGH) da Universidade do Estado de Santa Catarina (UDESC), no segundo semestre do ano de 2020. Em um primeiro contato com a professora Carla - a quem agradeço imensamente -, realizado via e-mail no dia 8 de setembro de 2020, tive a felicidade de receber em poucas horas sua resposta, e ela se disponibilizou a participar desta atividade. 
As pesquisas desenvolvidas pela professora Carla abordam diretamente dois pontos que me chamaram atenção e dialogam com minha pesquisa de doutorado: o uso da imprensa como fonte e a ditadura militar no interior do Paraná, sendo este último um tema ainda pouco explorado pela historiografia. Em minha pesquisa, pretendo abordar um jornal paranaense - Jornal Folha de Londrina - e seu posicionamento durante o período de redemocratização nacional, bem como seu possível diálogo com os documentos produzidos pelos agentes do Serviço Nacional de Informações (SNI).

Entre outros temas discutidos na sequência em entrevista com a professora Carla, temos o uso da imprensa como fonte historiográfica, os desafios dos pesquisadores e pesquisadoras no trato com as produções que circulam nas mídias sociais digitais, o trabalho dos historiadores e historiadoras diante das demandas sociais do tempo presente e características da ditadura militar no interior do Estado do Paraná.

Tempo \& Argumento: Atualmente, em quais grupos de pesquisa a professora está inserida ou em diálogo, sejam acadêmicos ou movimentos sociais, e com quais tem interesse em dialogar?

Carla Luciana Silva: Aqui na UNIOESTE, temos o grupo de pesquisa História e Poder $^{1}$, formado em 2005, e a linha de pesquisa Estado e Poder, na qual desenvolvemos diversas pesquisas nos cursos de mestrado e doutorado. Dos temas que aparecem na minha fala, muitos se remetem a pesquisas já feitas por outras pessoas, algumas que eu orientei. Sobre o nosso grupo de pesquisa, a linha na qual estou inserida trata de discussões que envolvem a direita e os mecanismos de reprodução do poder, por isso busco investigar temas como o fascismo, o bolsonarismo e o papel das redes sociais. Eu faço parte de um grupo coordenado pela professora Virgínia Fontes, que depois virou o grupo dos pesquisadores que trabalham nesta temática, congregando membros de todo Brasil. Este grupo está vinculado ao GT História e Marxismo da Anpuh, que existe desde 2005. Há três ou quatro edições da Anpuh, o simpósio temático é dobrado; são dois simpósios ao mesmo tempo, pois há uma grande quantidade de trabalhos sendo realizado. Eu também faço parte da rede de estudos Terrorismo de Estado. Na ocasião do meu pós-doutorado na

\footnotetext{
${ }^{1}$ Maiores informações sobre o Grupo de Pesquisa História e Poder, da UNIOESTE, disponíveis em: <https://www5.unioeste.br/portalunioeste/pos/ppgh/sobre/o-programa/laboratorios> <https://grupohistoriaepoder.com.br/>. Acesso em: 08 out. 2020.
} 
Universidade Nova de Lisboa, comecei a participar de um projeto coordenado pelo professor Manuel Loff, da Universidade do Porto, que reúne pesquisadores que abordam a temática da memória. Eu fiz o pós-doutorado com o Fernando Rosas, e dialoguei com pesquisadores que trouxeram uma grande discussão tirando o foco da questão francesa, sem nenhum menosprezo, para colocar o foco no problema da realidade das ditaduras ibéricas, fazendo esse debate muito mais vinculado à realidade das ditaduras da América Latina, como são os casos do Chile, da Argentina, do Uruguai e do Brasil. Além disso, sou militante da Rede Nacional de Comitês Memória, Verdade e Justiça. Neste momento, estamos fazendo uma rearticulação nacional do comitê, pois, atualmente, as políticas de memória estão sendo jogadas pela janela; cada semana acontece um fato novo relacionado a isso. Aqui em Marechal, nós temos o comitê Resistência e Solidariedade, que está buscando atuar para amenizar as consequências da pandemia na população mais pobre da cidade por meio da arrecadação e distribuição de cestas básicas e outros materiais. Além disso, nos esforçamos para criar uma escola de formação sindical visando ampliar este debate. Existe um grupo que também acompanho chamado Empresários e Ditadura, em conjunto com colegas, como os professores Pedro Campos, Eliane Bortoni e Rejane Hoeveler. Pedro Campos tem o livro premiado, Estranhas Catedrais², e as demais colegas também têm importantes trabalhos sobre o IPES (Instituto de Pesquisas e Estudos Sociais) e as redes internacionais que deram sustentação empresarial à ditadura no Brasil. Por fim, participo do NIEP (Núcleo Interdisciplinar de Estudos e Pesquisas sobre Marx) e do coletivo feminista Maria Lacerda de Moura, aqui em Marechal Rondon.

Tempo \& Argumento: A professora trabalhou com alguns veículos da imprensa como fontes de suas pesquisas, como a revista veja e a Folha de São Paulo. Gostaria de saber como a professora entende o papel da grande imprensa, em especial estes veículos de comunicação já consolidados, na construção de uma memória coletiva brasileira a respeito da última ditadura brasileira; há um traço comum nas narrativas destes meios de comunicação?

\footnotetext{
2 Ver CAMPOS, Pedro Henrique Pedreira. Estranhas catedrais: as empreiteiras brasileiras e a ditadura civil-militar, 1964-1988. Niterói: Eduff, 2014.
} 
Carla Luciana Silva: Eu estudei mais profundamente, por meio da revista veja e do jornal Folha de São Paulo, a relação da imprensa com a construção de visões que se transformam e ocupam o espaço de memória referente à ditadura. Não me atrevo muito a falar de outros veículos de imprensa. Existe um modus operandi da revista Veja que é muito particular e mostra que, ao tratarmos dos veículos de imprensa, existem ações que são contraditórias. A imprensa não é omissa, ela pode variar em alguns aspectos, como é o caso da Veja. A revista Veja, até o período que encerra a Comissão Nacional da Verdade (CNV), teve uma força política mais ampla. A conjuntura da falência da Editora Abril certamente levou a uma queda de influência da revista junto à opinião pública. Não é à toa que nas crises, inclusive no próprio impeachment em 2016, a revista não tem mais a força que tinha nos anos 1990, do ponto de vista da influência política. A década de 1990 foi o período que eu estudei na minha tese de doutorado. Percebi que ao longo de toda a década, no meio de matérias, de crises políticas e econômicas, apareciam notícias rememorando a ditadura militar. Percebi também que, na medida em que fui escrevendo e apresentando os resultados da investigação em eventos acadêmicos, sempre surgia alguém para dizer: "mas a revista Veja não era mais legal na época da ditadura?". Guardei essas falas para analisar depois, e acho que essa é uma característica que a gente tem de saber: o que vamos fazer naquele momento da pesquisa e o que vamos guardar para fazer em um outro momento. De certa maneira, foi o que eu fiz com as sugestões da época da ditadura, pois não tinha como abarcar tal discussão na tese. o que eu percebo é que existe uma situação em que a revista Veja tem uma postura diferente da Folha de São Paulo. Como é de conhecimento público, em 2009 a Folha de São Paulo lançou um editorial em que identifica o caso da ditadura brasileira como "ditabranda". A revista veja nunca escondeu, em seu editorial, que tenha acontecido uma ditadura no Brasil. Inclusive, durante a ditadura, existem algumas manifestações que são consideradas muito ousadas, como uma manchete que dizia que "o presidente não admite tortura". Tem algumas expressões, como um telefone quebrado, que não fala, não ouve e não vê, que é uma alusão à tortura, as pessoas que estão envolvidas, que na verdade, tecnicamente, era uma alusão à uma companhia telefônica. Entretanto, dentro da revista, quando abríamos para realizar a leitura, não só o editorial, quando folheávamos as matérias de cobertura sobre o que estava acontecendo no Brasil, na 
relação do Brasil com o mundo, percebíamos que a revista, sistematicamente, estava apoiando as medidas do governo, da ditadura. O projeto econômico estava sendo apoiado de forma bastante evidente. Há uma disparidade, pois um mesmo veículo pode ter determinadas ações num campo, mas com a linha editorial se comportando de maneira diferente. Eu percebi isso, por exemplo, no impeachment do Fernando Collor e também nos anos 2000, quando a revista Veja desempenhou um importante papel ao trazer o tema da tortura e dos torturadores em mais de um momento, destacando que o tema não deveria ser calado, e sim, investigado. Mas isso veio acompanhado de uma série de matérias que buscavam reiterar a importância dos militares, ou seja, "podemos até falar que isso aconteceu, mas não podemos avançar nas políticas de reparação e nas políticas de justiça”. Quem acompanhou entre 2009 e 2010 a discussão em torno do Programa Nacional de Direitos Humanos, percebe que a revista Veja se posicionou contra o ministro da justiça que tentou pontuar e questionar a interpretação que estava sendo dada para a lei de anistia de 1979. A capa da revista que saiu um dia depois da promulgação da lei de anistia de 1979 tem uma tarjeta escrito "página virada”. Essas são algumas das contradições do veículo, mesmo reconhecendo que excessos foram cometidos, sugere que a "página já foi virada" e que não é possível mexer nas feridas do passado. Ao falar isso, a revista também recoloca a ameaça de que os militares foram para casa, mas eles podem voltar a qualquer momento. Seria o famoso "pendurou as chuteiras", mas pode voltar, "está de pijama", mas pode voltar. Eu explorei bastante esse tema em alguns artigos, ${ }^{3}$ mostrando que em diferentes momentos tal questão vai reaparecendo e não tem como deixar de associar isso às políticas públicas e memoriais. Então, nesses diferentes momentos das políticas públicas de memória o tema volta: na lei de anistia, na lei 9.140 em 1995, a lei dos desaparecidos, na criação da Comissão de Anistia, em 2001, e, depois, evidentemente, culmina na Comissão Interamericana dos Direitos Humanos, que vai indicar uma comissão da verdade e depois volta com toda força na CNV. A Veja vai pegar inclusive a fala da própria presidenta Dilma Rousseff pra dizer que ela foi comedida, que está falando "vamos conhecer a verdade", mas essa história nós não queremos ir além disso. Diferentemente da Folha, que se colocou no

${ }^{3}$ Ver, por exemplo, SILVA, Carla Luciana. Veja e ditadura: a memória dos militares refaz a história. História Actual Online, n. 31, p. 95-107, primavera, 2013. 
jornalismo brasileiro em 1984 a partir das Diretas Já. Houve uma reestruturação organizativa da própria forma de produzir jornal, que aconteceu com o chamado Projeto Folha em 1984. O impresso procurou se construir como um jornal da democracia, ao contrário da Rede Globo e de todo aquele histórico de omitir o movimento das Diretas Já. A própria Folha de São Paulo dá espaço para essas movimentações, que são reiterativas no que diz respeito à existência da ditadura.

Tempo \& Argumento: Pensando no papel e influência das redes sociais digitais que observamos nos últimos anos, é possível pensar que os canais de comunicação tradicionais alteraram seu modo de agir e produzir conteúdo diante dessas novas plataformas?

Carla Luciana Silva: Seria interessante recuar, e já de antemão eu confesso que não tenho, neste último ano, acompanhado muito de perto a cobertura da grande imprensa, porque, como eu me dediquei nesses últimos meses a esta questão da ditadura aqui no Paraná, eu deixei essa discussão um pouco de lado. O que eu posso trazer para a discussão é pensar um fenômeno que aconteceu ainda no final dos anos 1990, na virada para os anos 2000. Podemos situar os governos do Fernando Henrique construindo esse processo chamado de neoliberalismo. No final desse governo, se estabelecem leis que permitem a abertura da imprensa brasileira para o capital externo, que até então não era permitido. Isso vai aprofundar o processo de abertura das empresas de comunicação para o capital externo, uma vez que não se vende apenas a empresa, mas também a produção de ideias e de conteúdo. o Grupo Folha foi o que se saiu melhor do ponto de vista do advento da internet, porque foi na década de 1990 que houve a aquisição do UOL, permitindo a junção do site com todos os outros mecanismos de produção de conteúdo. Por sua vez, a veja patinou em relação a isso, tanto que a Editora Abril veio à falência. Alguns autores colocam que a falência ocorreu não só pelo modelo de organização, como era o caso do Grupo Abril, que contava com o maior parque gráfico da América Latina, mas por ser administrado de uma forma familiar. Há uma contradição com todo o discurso que a revista Veja ajudou a construir, com a revista Exame e toda a Editora Abril em relação à maneira como deve ser feita a reestruturação das empresas. Então, ela teve um 
grande prejuízo entrando no mundo da TV, que era a TVA, para concorrer com a SKY. Enquanto isso, o Grupo Folha foi adiante. A Veja tentou reverter isso com os blogues. Durante os governos do Lula, é possível acompanhar o surgimento de figuras que vão se tornar conhecidas posteriormente pela disseminação de fake news; sujeitos que dizem e escrevem o que bem entendem e passam a não ter nenhum compromisso com a realidade, são os autoproclamados filhos de Paulo Francis, os polemistas. O Diogo Mainardi e o Reinaldo Azevedo, por exemplo, começam a produzir e a criar expressões como "petralha" e "Lula minha anta". O uso dessas expressões absurdas que se generalizam tem início ali no blog da Veja. Posteriormente, surgem problemas internos e rupturas dessa relação da Editora Abril com o PSDB. Diogo Mainardi vai ser processado, assim como Paulo Francis já tinha sido, enfim, esse sistema ali com eles não dá muito certo, ainda existe algum padrão de verdade que está colocado contra eles. Mas na década de 2010, tal processo vai crescendo, porque há um protagonismo maior das redes sociais. Tivemos um marco fundamental na criação do Mídia Sem Máscara, site do Olavo de Carvalho. Ali ele se torna uma figura pública e começa a fazer experimentações, sem ter noção do alcance possível que aquele tipo de material teria. Se somarmos todos os outros elementos, os aparelhos privados de hegemonia que estão produzindo visões de mundo, que vão alimentar esses grupos, chegaremos à conclusão de que o papel deles, de modo muito geral, é isso. Não há uma novidade ao se pensar sobre o pensamento de massas, isso tem cem anos pelo menos. Quando a gente lê a literatura sobre o final do século XIX esse estranhamento dos intelectuais em relação ao surgimento do jornal, se equivale a esse delay que existe entre conhecer as redes sociais e saber como agir com elas. É um pouco equivalente, me parece, com aquele estranhamento que aconteceu lá no final do século XIX. Então, o que a gente tinha do ponto de vista da criação de ideias, inclusive de ideias contra-hegemônicas até o começo dos anos 1990, se colocava assim: como vamos construir um jornal que pense ideias alternativas, o próprio dilema do MST (Movimento dos Trabalhadores Rurais Sem Terra) quando criou o jornal Brasil de Fato, e por onde vamos realizar a distribuição. Como faremos com que esse jornal chegue no país inteiro? Quem é que tinha uma rede de distribuição que pudesse atingir o país inteiro? Portanto, o MST até poderia produzir seu próprio material, mas sem dar o passo seguinte, que era fazer a circulação. 
Muitas vezes, isso não era nem rodado dentro das gráficas, caracterizando-se como um dilema que os sindicatos tinham, e ainda têm, em grande medida, quando as gráficas se recusam a fazer a rodagem e a circulação do material. Isso significativamente muda com as redes sociais, porque as redes sociais permitem a circulação. É um pouco o argumento que a direita usa, ao alegar que "ninguém nos lia, agora nos leem". Enfim, a possibilidade de produção, de disseminação de conteúdos e de ideias é incomparável. Quando você tem que produzir um jornal, rodar um jornal, mandar pelo correio, é diferente de você abrir o computador e estar tudo ali, sem ter o direito do contraditório e tudo mais.

Tempo \& Argumento: Durante a ditadura militar a grande mídia teve um papel relevante na construção de consensos sociais. Com o advento da internet e a emergência das redes sociais, verificamos uma capilarização das estruturas de proliferação de fake news. Que desafios uma pesquisadora interessada no papel da imprensa encontra ao tratar desse assunto na atualidade e em que medida ele se diferencia da abordagem da imprensa durante o período da ditadura militar?

Carla Luciana Silva: Eu acho que esse é um tema que deveríamos aprofundar. O que vou dizer é uma hipótese, que trabalha mais por um aspecto da questão que é pensar que fake news é um nome novo para um fenômeno antigo, tendo como pano de fundo que nós sabemos que isso que se chama fake news tem um poder de disseminação ampliado por esse aspecto que eu falei anteriormente, ou seja, a capacidade de disseminar conteúdo que não existia sem as redes sociais. Por que estou dizendo que é uma velha questão? A historiografia da imprensa discutia, inclusive uma historiografia que debate por dentro do jornalismo, o paradigma da manipulação, da imprensa como manipuladora, e alguns autores criticavam dizendo: "nossa, vocês veem manipulação em tudo!". Então eu pergunto: o que é uma fake news se não uma manipulação? Manipulação passa muitas vezes pela produção de mentira em notícias. Mas isso sempre aconteceu. Como isso se dá na imprensa? A gente tem fatos jornalísticos que são produzidos. Na imprensa jornalística, para pegar os veículos impressos e não a televisão que seria um outro eco de possibilidades, temos o uso da fotomontagem como recurso. Eu volto pra revista Veja e a 
criação de matérias que reproduzem uma lógica que, se não tivesse na capa da revista, hoje seria um meme perfeitamente. Quando a revista Veja coloca Fernando Henrique Cardoso assumindo o governo, enfrentando a greve dos petroleiros em 1995, com capacete de militar e uma roupa militar e exaltando o comando forte do então presidente, o que é isso se não um meme pronto? Com certeza se fosse na época do WhatsApp essa figurinha iria circular por todo lado. O poder de disseminação de uma coisa e de outra é imenso. O caso da Veja é interessante porque na capa da revista, que é um espaço icônico por natureza, não havia o costume de identificar aquele material como uma fotomontagem, pois se tratava de um dos recursos mais comuns das capas. Lá dentro, quando se lê o editorial, a Carta ao Leitor, você tem algum indício de como o material foi produzido, mas ele não é identificado dessa forma, portanto ele é uma fake news. Ele traz uma informação mentirosa, Fernando Henrique nunca usou aquela roupa, e ela traça o adendo de uma fala, reiterando a posição do presidente. Quem estudou o processo eleitoral, sabe da capa prévia das primeiras eleições do Lula em 2002, em que há um cérbero com as cabeças guardando as portas do inferno, Trotsky, Lênin, Evo Morales, Hugo Chávez, enfim, elas se retroalimentam. Isso é fake news. Portanto, temos uma hipótese a ser explorada de que o fenômeno da manipulação é um fenômeno bem anterior. Quando visualizamos a fotografia denunciando o falso suicídio do Herzog, que não foi um suicídio, temos o mesmo fenômeno, que é de dizer que houve um suicídio numa situação que é impossível que ele tenha ocorrido. Sobre o artigo que eu produzi a respeito do "suicídio da presidenta", na ocasião era uma novidade que as redes de WhatsApp fizessem e tivessem o poder que têm. Elas são um meio de comunicação que impossibilitam que você chegue na origem da produção. Ela só vai, ela não volta. O poder que ela tem é imenso e, ao mesmo tempo, a nossa capacidade de verificabilidade, inclusive de pesquisa, é muito diferente, porque não conseguimos rastreá-la. Mas tivemos vários momentos na própria ditadura, por exemplo, quando foram produzidos aqueles vídeos de pessoas que são, entre aspas, arrependidas, pessoas que muitas vezes são torturadas, ameaçadas para irem à TV dizer que se arrependiam de ter feito a luta armada, essas pessoas eram maquiadas, eram penteadas, elas ganhavam outras roupas. O que é isso se não a produção, a manipulação de uma imagem e de uma ideia, pra passar essa ideia que eles estavam querendo transmitir? E ao 
mesmo tempo a imprensa, o tempo inteiro durante a ditadura, agiu não só como corrente de transmissão. Quando a Veja coloca os cartazes de procurados pra tentar encontrar certas pessoas, ou então quando coloca a foto do Marighella, dizendo que ele pode se encontrar aqui, só falta dizer "ajude a encontrá-lo”. Ou então quando a ditadura é obrigada a soltar as pessoas que foram trocadas no sequestro dos diplomatas, ocasião em que essas pessoas são maquiadas e recebem comida. Claro que isso tem pouco efeito, porque você olha algumas dessas pessoas e vê que elas não conseguem parar em pé, elas estão absolutamente quebradas pela tortura. Portanto, a imprensa teve esse papel de manipulação, ora segurando informação, ora divulgando informações somente quando era de interesse da ditadura, como quando aconteceu quando Lamarca desertou do Exército. Trata-se de uma série de elementos que podemos caracterizar como manipulação. No entanto, a manipulação vem junto com a visão de mundo que a forma. Esses dois elementos estão associados.

Tempo \& Argumento: Para além do aparelho repressivo do regime militar, que muitas vezes ganha destaque nas pesquisas sobre a ditadura, sabemos que havia também um projeto de sociedade amplo, que perpassava várias áreas. Em suas pesquisas, a professora consegue perceber a construção de um projeto de sociedade que perpassou por áreas como a cultura, a educação e a economia, e que permaneceu ativa durante o período de redemocratização e posteriormente?

Carla Luciana Silva: Talvez a maior marca seja a legitimação e a aceitação da violência, da repressão por parte do Estado. Eu sempre gosto de lembrar dos crimes de maio, que são denunciados pelas mães de maio em São Paulo, em 2006. Em duas semanas, foram assassinadas quase tantas pessoas quanto foram na ditadura em números oficiais. Essa é a grande marca que a ditadura deixou. Que não nos parece como grande marca da ditadura, mas é. Dentro do Estado Democrático, esse aparelho repressor foi mantido, graças a determinados elementos como a impunibilidade dos repressores e a aceitação dos crimes de lesa humanidade, que não são denunciados, ou que não há justiça sobre eles. É preciso um longo trabalho dos familiares na Comissão Interamericana de Direitos Humanos para ir aos pouquinhos puxando um fiozinho relacionado a isso. No entanto, me parece que tem um 
grande elemento que foi estruturante da aceitação mais ampla do golpe que retornou com muita força: o elemento do anticomunismo. Essa questão é latente na sociedade brasileira desde os anos 1930. Em determinados momentos esse elemento é trazido de volta, isso ajuda a entender o golpe. Mas a ditadura não tem um projeto de nação próprio, como pode parecer. Existe um incentivo muito grande ao patriotismo, existe a repaginação da agência de propaganda, que foi estudado por vários autores, que vão reproduzindo o 7 de setembro, por exemplo. Esse material está presente lá nos livros didáticos. Eu fui educada durante a ditadura no ensino primário; a gente tinha que saber quem eram os presidentes, não existia a palavra ditador, enfim, não se falava na ditadura. Eu acho que a grande jogada que a ditadura conseguiu fazer pra si, pra que acontecesse esse esquecimento sobre ela, foi o fato de que ela se construiu enquanto uma democracia, ela se dizia democrata. Os atos institucionais diziam: "a revolução gloriosa para instituir a democracia". Esse jogo de palavras não é em vão, tem uma fundamentação, assim como o uso do patriotismo e do futebol como um elemento de criação de identidades. Do ponto de vista geral, a questão do milagre econômico foi menosprezada pelos próprios grupos que faziam resistência à ditadura, por não pensar em como ele consegue criar um mecanismo que cola na população de uma forma mais geral. A construção das grandes obras da ditadura ajudou a criar a ideia de desenvolvimento, de nação, de país grande, essa coisa de país que vai pra frente. Transamazônica, Ponte Rio-Niterói, Usina de Itaipu, todos esses elementos estão levando a uma reestruturação do Estado, estão levando a poupança forçada do FGTS (Fundo de Garantia do Tempo de Serviço), por exemplo. Isso vai ter uma relação direta com a classe trabalhadora, não é à toa que vão explodir as greves em 1979. Porque isso estava levando a um arrocho cada vez maior da classe trabalhadora. É importante da gente dizer: a ditadura brasileira tinha elementos fascistas, mas o projeto dela não era um projeto fascista totalitário. Ela não estava tentando criar grupos de milícias para fornecer uma sustentação mais ampla. Pelo contrário, o regime militar pretendeu exterminar qualquer manifestação popular existente. São justamente esses grupos que vão explodir durante o período de redemocratização, como os clubes de mães, as comunidades eclesiais de base, ou seja, a emergência de uma sociedade civil organizada. Os militares conseguiram até certo momento controlar a luta da resistência, mas não conseguiram controlar esses outros grupos. 
Houve uma relação ambígua com o próprio movimento estudantil durante toda a ditadura, porque o movimento que criou militantes que fizeram resistência, precisava de espaços de manifestação controlados, que não explodissem mais do que já haviam explodido. Dessa forma, constatam-se elementos de continuidade da ditadura, a violência é um elemento de continuidade da ditadura, porém a ditadura enquanto construtora de uma visão de mundo, eu não vejo dessa forma. Tanto é que o movimento das Diretas Já se constrói recuperando os próprios símbolos nacionais. Há uma disputa sobre essa simbologia para trazer um novo significado. O Henfil falava sobre o futebol: "eu quero poder torcer pelo meu país". Então não foi uma "terra arrasada" no sentido da construção de um projeto de nação que a ditadura conseguiu. Quando analisamos um pouco mais a fundo, percebemos a existência de corrupção dentro do estado reorganizado pela própria ditadura. No caso do oeste do Paraná, por exemplo, os movimentos muito fortes existiram, não contra a construção da Itaipu, mas em decorrência da construção da Itaipu. Os movimentos dos atingidos por barragens acontecem exatamente onde estão sendo feitas as hidrelétricas que trazem o "desenvolvimento". A ditadura, de certa forma, retoma um projeto desenvolvimentista, só que com uma nova roupagem. Esse projeto na ditadura vai ser a plena abertura para o capital financeiro, para o capital internacional que estava ocupando o campo financeiro e que vai redundar no endividamento do país, na inflação, na crise dos anos 1980.

Tempo \& Argumento: Em sua pesquisa sobre a ditadura, no projeto que buscou pensar este período, mais propriamente no interior do estado do Paraná, espaço não tão investigado como as grandes cidades, a professora percebe diferenças ou semelhanças do que as pesquisas apontam que ocorria nos grandes centros? É possivel perceber alguma singularidade a respeito da ditadura no Paraná?

Carla Luciana Silva: A minha experiência de pesquisa me mostrou parte de uma peculiaridade que é o fato de que, como eu tentei investigar a região oeste do Paraná, uma região de longa fronteira, partia da ideia de que era uma região do interior, mas é um interior que dialoga não só com o restante do país, é um interior que dialoga internacionalmente. Essa á a grande característica dessa região do Paraná. Eu trabalho com 
outros colegas em outras regiões do Brasil com a ideia de "ditadura fora do eixo". Fora do eixo Rio-São Paulo, como também fora do eixo historiográfico dominante sobre a ditadura; é uma referência que estamos construindo. Para pensar aqui, se a gente pegar toda a região oeste, o próprio Mato Grosso do Sul, o Mato Grosso, se a gente descer para o sul, vamos ver uma longuíssima região de fronteira, que vai até o sul do Rio Grande do Sul, na divisa com o Uruguai, e que os grupos usam esses espaços, tanto os grupos que estão fazendo resistência, de diferentes formas, temos estudos que estão mostrando isso, como também a ocupação pelos órgãos de repressão. Quando alguém pega, por exemplo, a documentação do CIEX, o Centro de Inteligência do Exército, a gente fica assombrado com a quantidade de materiais que existe sobre essas pequenas cidades, pequenos espaços que são espaços de movimentação, muito além de Foz do Iguaçu, que é um espaço maior, é evidente, temos ali a tríplice fronteira, mas a gente tem Guaíra aqui, mais especificamente. Qual o quadro do interior? É um quadro de lutas pela terra. O que atrai grupos aqui para a região nos anos 1960 é a existência prévia de grupos que lutaram pela terra, seja o movimento de posseiros, que depois vai dar lá no MST (Movimento Sem Terra), no MASTRO (Movimento dos Agricultores Sem Terra do Oeste do Paraná), tendo um espaço importante de criação aqui. A CPT (Comissão Pastoral da Terra), com uma atuação muito forte, atuando junto aos desabrigados da Itaipu. Isso vai trazer grupos políticos específicos, com o nascimento do MDB (Movimento Democrático Brasileiro) na região. Movimentos de luta dentro do Parque Nacional do Iguaçu, não só de luta pela Estrada do Colono, mas espaços que, salvo engano, ainda não foram estudados, como disputas por terra dentro do parque nacional, disputas com as companhias madeireiras. O problema da terra, da questão agrária, é fundamental para problematizar a região. Descobrimos, em diferentes pesquisas, a existência de um grupo tático da VAR-Palmares (Vanguarda Armada Revolucionária-Palmares), em 1969, em Nova Aurora. O grupo do MR8 sai do Rio de Janeiro e vem pra cá com a crença de que existiria ali uma guerrilha rural e que a luta começaria com ela. Temos esses diferentes movimentos acontecendo aqui também. Na região de Boipiquá, entre Cascavel e Medianeira, mais ou menos a gente tenta mapear essa luta ali. E, em 1974, a chacina do Parque Nacional, com seis militantes mortos. Perceba que eu comecei a investigação tentando contribuir com essa pesquisa sobre o Parque Nacional e eu fui acabar pesquisando nos arquivos do Ministério das Relações 
Internacionais lá em Santiago, no Chile. É uma pesquisa que parecia ser local; primeiro, fui para Brasília e depois fui para Buenos Aires, mas essa chacina que aconteceu no Parque Nacional, por exemplo, tem o assassinato de um jovem argentino de 18 anos, Enrique Ernesto Ruggia, que veio para cá e acabou assassinado. Então, comecei dialogando com a irmã dele, lá em Buenos Aires, e procurando materiais nos jornais. Há um trânsito dos militantes que saem do interior do Brasil e vão pra esse corredor que passa por alguns pontos do Uruguai e da fronteira da Argentina, seja no Paraná, seja em Santa Catarina, mas especialmente depois, no Rio Grande do Sul, porque os diferentes grupos que faziam as lutas de resistência, seja a ALN (Ação Libertadora Nacional), seja a VPR, seja o MNR (Movimento Nacionalista Revolucionário), eles tinham diferentes pontos. Essa região, esse nosso interior, apresenta um movimento que vai muito além do problema regional, é um movimento que em grande medida é internacional. É uma história que é "fora do eixo" no sentido mais conhecido, mas que traz esses conflitos e essas contradições, e aquele problema fundamental que é: para instituição da luta armada existe uma relação entre campo e cidade e ela deve começar no campo, mas os grupos tinham uma visão do campo que era muito distinta da realidade do próprio campo. Não era porque tínhamos ali a existência prévia dos movimentos dos posseiros, por exemplo, que eles iriam se transformar em grupos de guerrilha. É uma relação que a gente tem contribuído e estudado sobre esse movimento.

Tempo \& Argumento: A respeito do uso das mídias como fonte de pesquisas históricas, a professora publicou na revista Antíteses, em 2017, um artigo com o título "O suicídio da presidente: a arte da mentira e a criação do consenso na grande imprensa brasileira". Esse artigo aborda questões sobre os desafios dos historiadores ao utilizarem a imprensa como fonte de pesquisa, em especial apontando para as concepções de verdade e mentira. Como a expertise do historiador(a) pode ser reivindicada e aplicada em situações como essa, de forma a contribuir tanto para o maior conhecimento da história, quanto para o aprimoramento da cultura política no tempo presente?

Carla Luciana Silva: Excelente questão. Ela tem um vínculo com a discussão sobre uma concepção de História do Tempo Presente (HTP) que a 
gente vai falar depois, mas fundamental é colocar o problema da relação entre verdade e mentira, ou, melhor dito, a nossa relação com a ideia de verdade e com a ideia de mentira. Existe uma corrente de pensamento que já problematizou essa questão há muito tempo, não só na filosofia, mas nas ciências sociais de forma mais ampla. Não podemos cair nessa resposta fácil de eliminar a possibilidade nem da mentira nem da verdade. Não quero dizer que eu acho que a gente se sente "dono da verdade", mas algumas verdades existem, algumas verdades dentro da problematização que nós historiadores fazemos. Nosso referencial teórico e metodológico está ali pra nos ajudar a colocar isso. Esse é um horizonte que passa por recolocarmos o papel dos conflitos e contradições, imanentes aos fatos sociais. A história não tem só um lado, claro, porque os sujeitos que estão envolvidos nos embates sociais estão muitas vezes representando projetos sociais diferentes, com posições sociais e políticas distintas. Nos acostumamos, mesmo sem perceber, a reiterar determinadas histórias de uma forma dominante, mesmo quando estamos contando a história dos dominados. A história dos vencedores oculta os vencidos, oculta o conflito que existiu mesmo antes que aquela vitória tenha ocorrido. Se a gente for pensar de uma forma mais ampla, esse discurso que vai sendo construído nos anos 1990, de que o capitalismo venceu, de que não existe alternativa, ele insiste exatamente nisso, não só em construir essa vitória, como em apagar o passado e construir uma versão sobre o passado daquele que teria sido, e que foi, o vencido, em diferentes aspectos. Estudando agora os movimentos de luta armada, percebemos que há muitas coisas que devem ser compreendidas, muitos detalhes que não são detalhes, mas posições, definições, discussões foram abortadas e às vezes a gente olha enquanto historiador e só tem um documento de um grupo de mulheres, de uma mulher que escreveu e a gente pensa, isso não tem importância, é só um documento de uma pessoa só. Como não tem importância? Recuperar a dissidência ajuda a pensar que a verdade é estabelecida por esse embate, por essas diferentes posições que estavam em disputa. Nesse sentido, também temos o desafio de recuperar o lugar da mentira, não só da verdade, a mentira, ela é um pouco dessa provocação. Se estou trabalhando com manipulação, eu vejo mentira o tempo inteiro, mas quais são os recursos que posso usar? Eu trabalho com os recursos em que busco recuperar uma concepção de ideologia, usando meios que me permitem fazer análises 
do discurso, que me permitem problematizar o discurso, trazer o discurso como instrumento de análise teórica e histórica. Eles estão mediados pelo concreto, pela realidade, com uma noção de totalidade na minha visão, e a partir daí problematizamos a fonte.

Tempo \& Argumento: Neste mesmo artigo, os desafios no trabalho com a imprensa aparecem alinhados aos desafios implicitos na escrita da História do Tempo Presente. Como a professora entende o papel político das historiadoras e historiadores frente às demandas sociais do presente, em especial ao tratar de temas traumáticos e, em alguns casos, indesejados?

Carla Luciana Silva: Sei que vocês estão aprofundando a discussão da HTP, sei que vocês produzem eventos e discussões aprofundadas sobre isso. $O$ que vou colocar aqui é uma visão, uma corrente, digamos assim, de pensamento relacionada a isso. A minha leitura sobre isso começou na minha graduação na UFRGS, com o professor Enrique Padrós; acho que foi a primeira vez que ouvi falar de HTP, e na época se usava bastante a expressão "história imediata", então tinha uma discussão sobre a diferenciação entre uma coisa e outra. Essa formação muito dada na história contemporânea me coloca em diálogo sempre com algumas provocações que o historiador britânico Eric Hobsbawm fez ao longo de sua obra, ou seja, a de colocar a questão do engajamento do historiador. Eu parto da ideia de que a HTP sempre foi feita, sempre existiu. Historiadores, pessoas contando a sua própria história, desde Heródoto, Hesíodo, desde a Antiguidade, as pessoas se colocando esse desafio de escrever a história do tempo em que ela está vivendo. Quando trabalhamos com a imprensa, percebemos um problema adicional que é: durante muito tempo, os historiadores construíram uma ideia de que não era seu papel escrever a história desse tempo, apesar de todo o histórico de escrita da história, e isso leva a uma defasagem no sentido de que quem acaba escrevendo esta história é a imprensa. Se olharmos em muitos editoriais de grandes jornais, como o New York Times, vamos ver eles dizendo que estão escrevendo um rascunho da história, para que depois os historiadores a passem a limpo. A imprensa tomou pra si este papel, de dizer que a história recente, a história que está acontecendo agora é ela que está contando. Se a gente tem uma análise crítica da imprensa não tem 
como a gente aceitar isso, mas parece que houve um longo processo em que os historiadores permitiram, de certa forma, ou colocaram dificuldades ou não viram como seu papel fazer essa história. Muitas vezes a própria ida ao jornal como fonte acaba sendo a busca de uma verdade, do que aconteceu, acho que a gente já superou isso com trabalhos críticos sobre a imprensa. Mas se formos pensar historicamente, o que é o Dezoito Brumário ${ }^{4}$ de Marx se não uma história do tempo presente. Ele está contando e problematizando aquela história em relação ao momento que ele está vivendo. O problema adicional quando propormos temas sensíveis para discutir, como a ditadura, é que no momento da redemocratização do Brasil, a gente tem uma história escrita não por historiadores, e sim por cientistas sociais. Quando a gente para pra pensar quais são os temas fundadores da história da ditadura, a gente vai chegar no René Dreifuss $^{5}$, sobre a redemocratização temos Bernardo Kucinski ${ }^{6}$, que escreveu um livro genial, mas ele é jornalista. Destaco também uma referência dentro deste campo e que nasceu dentro da grande imprensa, que é o jornalista Elio Gaspari. Elio começou escrevendo para a Editora Abril e depois passou por vários jornais e revistas. Por proximidade com as fontes que vão ficar sobre a sua própria guarda, escreveu uma história que retoma muito do brilhantismo dos militares, como de que Geisel era um "general instruído". Sobre toda essa visão que vai se construir sobre a ditadura, me parece que a obra do Elio Gaspari tem um peso enorme. Quando perguntamos para alguém fora da academia o que eles leram sobre este período, é muito mais provável que eles citem Elio Gaspari do que os nossos trabalhos. Não vamos entrar aqui em problemas nossos contra os jornalistas, não é isso, a questão que nós estamos tentando discutir é de quando a historiografia começa a produzir. Os jornalistas, de uma forma geral, ocuparam esse espaço de escrever, mas a gente sabe a diferença que existe para nós historiadores na concepção de fonte e na concepção dos jornalistas, são universos quase que opostos. Eles têm fidelidade à fonte acima de tudo, e nós sabemos que temos que problematizar a nossa fonte. O que tem muito a ver com essa construção que foi feita

\footnotetext{
${ }^{4}$ MARX, Karl. O Dezoito Brumário de Louis Bonaparte. São Paulo: Centauro, 2006.

5 DREIFUSS, René Armand. 1964: a conquista do Estado - ação política, poder e golpe de classe. Petrópolis: Vozes, 1981.

${ }^{6}$ KUCINSKI, Bernardo. Abertura, a história de uma crise. São Paulo: Brasil Debates, 1982.

O jornalista Elio Gaspari produziu uma coleção de cinco livros que abordam a questão da ditadura brasileira, nos quais trata desde as articulações ocorridas nas vésperas do golpe de 1964, até o fim do regime civil-militar, com a eleição de Tancredo Neves, em 1985.
} 
antes por esses autores, uma dada ideia de que nos anos 1980 a redemocratização significou toda a sociedade brasileira unida, a sociedade contra o Estado, por exemplo, essa ideia é uma falácia. Isso foi uma grande construção. Quando a gente pega a obra da historiadora Virgínia Fontes ${ }^{8}$, a gente vê os estudos que ela foi trazendo para mostrar que este entrar da sociedade foi uma construção discursiva no sentido de apagar as contradições e de construir uma ideia muito idílica do que seja a sociedade. Como se dentro da sociedade só houvesse os movimentos sociais que foram lá e construíram a luta pelas Diretas Já e fossem todos iguais, e que os interesses fossem exatamente os mesmos, da classe trabalhadora à burguesia industrial, ou da burguesia comercial que estava ali precisando de uma nova reestruturação produtiva para dar um novo passo na acumulação produtiva. Essa visão estereotipada que se construiu, os historiadores, muito recentemente, têm conseguido limpar. Claro que se soma a isso a produção dos próprios militares sobre sua história e a história da ditadura. Eles começam a dar passos largos, seja o Ustra, Giordani, que vão escrever a história dos próprios militares, redundando no fato da Folha de São Paulo construir essa bobagem da "ditabranda". Não é um termo que a Folha tenha criado, é um termo que vem lá das ciências sociais, e que por uma série de definições consegue distinguir uma ditadura mais dura de uma ditadura mais branda?.

Tempo \& Argumento: Pensando em uma questão mais prática, ao tratar da imprensa, com qual, ou quais teorias a professora dialogou ou tem dialogado? Como chegou a determinados marcos teóricos e como os aplica em suas análises?

Carla Luciana Silva: Este debate veio, na minha concepção, com toda essa formação que vem lá da graduação e vai passando por uma construção mais ampla, que começa com uma leitura do chamado "pensamento crítico" que se coloca dentro da discussão do "não há alternativas", ali nos anos 1990, com a discussão que é trazida para o Brasil pelo Le

\footnotetext{
${ }^{8}$ FONTES, Virgínia. O Brasil e o capital-imperialismo: teoria e história. Rio de Janeiro: Editora UFRJ, 2010

${ }^{9}$ Várias discussões sobre este tema foram realizadas nos livros: MELO, Demian (Org.). A miséria da historiografia: uma crítica ao revisionismo contemporâneo. São Paulo: Consequência, 2014. e SENA JUNIOR, Carlos Zacarias de; MELO, Demian Bezerra de; CALIL, Gilberto Grassi (Orgs.). Contribuição à crítica da historiografia revisionista. São Paulo: Consequência, 2017.
} 
Monde Diplomatique ${ }^{10}$. Todo um movimento que está vinculado à teoria crítica da escola de Frankfurt, que é a origem das discussões que estão colocadas ali e que buscam trazer elementos para recolocar o papel e a importância de se fazer uma discussão sobre esse momento da HTP. Eles vão traduzir autores, como o Ignácio Ramonet ${ }^{11}$, depois vão ter outros que seguem essa linha e que têm até hoje uma influência no jornalismo de esquerda, no jornalismo crítico do Brasil e que retoma aspectos do marxismo, que são necessários, que são elementos que também apareciam nos estudos sobre discurso. A análise do discurso francesa traz um leque imenso de possibilidades, de mostrar a produção de sentido e de como é que a fala e a linguagem têm poder e de como somos capazes de captar isso em diferentes sentidos. Aquela crítica que se fazia, de que a verdade não existe, ela redunda em pessoas dizendo que vacina não importa, ou então que vacina faz mal, ou dizendo que o kit-gay existe. São elementos que parecem bobagem, pessoas acreditando em "mamadeira de piroca", o que é isso se não uma grande mentira transformada em verdade na mente dessas pessoas? Tem um fundamento político e uma influência política imensa. Todos esses elementos enquanto conceito, o conceito de ideologia e o instrumento de análise do discurso, ajudam na problematização dessas questões. A análise de discurso francesa retoma algumas ideias que vinham lá do Althusser, quando colocamos esse autor, há um problema com a concepção de ideologia, em que as pessoas o recebem de forma muito reativa. Ela nos ajuda, mas ela é limitada, então buscamos fazer um diálogo com ela aprofundando as propostas que Antonio Gramsci faz ao trazer a noção de hegemonia, que vai trabalhar a noção de consenso aliada à noção de coerção, as duas coisas andam juntas. Esse é o grande insight. o Estado e a sociedade civil, o Estado se ampliando, se abrindo, trazendo os conflitos que estavam na sociedade, nas lutas, nas comunidades de base, para dentro de comitês que vão tirar a luta da rua e colocá-la dentro deste espaço específico. A junção desses autores vai construindo uma visão de uma HTP e que permite amarrá-la com a discussão que eu tinha colocado antes, de pensar uma sociedade constituída de conflitos, que são conflitos de classe, de raça, de gênero, de todos esses elementos constituintes dessas contradições. Os empresários também são parte da sociedade, os capitalistas também

\footnotetext{
10 Ver RON, José Manoel. Pensamiento Crítico vs. Pensamiento Único. Madrid: Ed. Debate, 1998 ${ }^{11}$ Ignácio Ramonet é jornalista e sociólogo espanhol, foi diretor da edição francesa do Le Monde Diplomatique entre 1990 e 2008.
} 
fazem parte de uma forma conflituosa na disputa de discursos e tudo mais. Perceba-se que a própria análise de discurso também faz uma aproximação com a psicanálise ao trazer o elemento que origina, que já tinha sido tipificado como indústria cultural, e como a indústria cultural ajuda na formação da personalidade autoritária. Tivemos recentemente a tradução do texto do Adorno ${ }^{12}$ no Brasil, uma importante contribuição pra desconstruir aquela ideia de que elementos autoritários ou fascistas surgiram nos anos 1980 ou 1990. O que é que o estudo do Adorno nos mostra? Que esses elementos estavam presentes no pós-Segunda Guerra Mundial. A história constrói uma visão que mostrou um pós-Segunda Guerra sem conflitos, e é óbvio que isso não aconteceu. Os vencedores ganharam, mas eles não destruíram completamente os perdedores, suas ideias permaneceram lá. A ideia de hegemonia nos permite perceber as permanências dessas ideias como se estivessem ali mantidas perenemente, para que em algum momento, dentro de uma dada conjuntura, de uma relação de forças, elas possam voltar. Trazer essa discussão da sociedade de massas, da forma que Freud transforma no "mal-estar da civilização", são elementos muito importantes, e Gramsci nos traz o elemento do americanismo e fordismo ${ }^{13}$. Retomando um aspecto quando falava das consequências da ditadura, do que ela deixou muito firme na sociedade brasileira, é a sociedade brasileira como uma sociedade de consumo, que necessita consumir cada vez mais. E esse consumir cada vez mais vai levar à mercantilização de vários aspectos da vida, à ideia de americanismo e fordismo que pensam uma visão de mundo e uma estrutura organizativa e social para que essa mesma possa existir. Esses são os referenciais teóricos mais amplos, que me permitem pensar como trabalhar com essa HTP, que trabalha com a ideia de processo, de totalidade histórica, mas que percebe como é que esses conflitos estão presentes neste momento específico que estamos analisando. É difícil, estamos vivendo uma pandemia, analisar esses elementos é muito difícil, mas é um desafio que está colocado para a gente. Nós, historiadores e historiadoras, precisamos estar à frente dessa discussão.

\footnotetext{
12 ADORNO, Theodor W. Estudos sobre a personalidade autoritária. São Paulo: Editora Unesp, 2019 [1950].

${ }^{13}$ Ver GRAMSCI, Antonio. Americanismo e fordismo. Rio de Janeiro: Civilização Brasileira, 2001.
} 


\section{Referências}

ADORNO, Theodor W. Estudos sobre a personalidade autoritária. São Paulo: Editora Unesp, 2019.

CAMPOS, Pedro Henrique Pedreira. Estranhas catedrais: as empreiteiras brasileiras e a ditadura civil-militar, 1964-1988. Niterói: Eduff, 2014.

DREIFUSS, René Armand. 1964: a conquista do Estado - ação política, poder e golpe de classe. Petrópolis: Vozes, 1981.

FONTES, Virgínia. O Brasil e o capital-imperialismo: teoria e história. Rio de Janeiro: Editora UFRJ, 2010.

GRAMSCI, Antonio. Americanismo e fordismo. Rio de Janeiro: Civilização Brasileira, 2001.

KUCINSKI, Bernardo. Abertura, a história de uma crise. São Paulo: Brasil Debates, 1982.

MARX, Karl. O Dezoito Brumário de Louis Bonaparte. São Paulo: Centauro, 2006.

MELO, Demian (Org.). A miséria da historiografia: uma crítica ao revisionismo contemporâneo. São Paulo: Consequência, 2014.

RON, José Manoel (Dir. Col.). Pensamiento Crítico vs. Pensamiento Único. Madrid: Ed. Debate, 1998.

SENA JUNIOR, Carlos Zacarias de; MELO, Demian Bezerra de; CALIL, Gilberto Grassi (Orgs.). Contribuição à crítica da historiografia revisionista. São Paulo: Consequência, 2017.

SILVA, Carla Luciana. Veja e ditadura: a memória dos militares refaz a história. História Actual Online, n. 31, p. 95-107, primavera, 2013.

SILVA, Carla Luciana Souza da. O suicídio da presidente: a arte da mentira e a criação do consenso na grande imprensa brasileira. Antíteses, Londrina, v. 10, n. 19, p. 332-350, jan./jun. 2017.

Universidade do Estado de Santa Catarina - UDESC

Programa de Pós-Graduação em História - PPGH

Revista Tempo e Argumento

Volume 13 - Número 32 - Ano 2021 tempoeargumento@gmail.com 